\title{
EL DESARROLLO COMUNITARIO EN EL DECRETO 3524/1974
}

301.185.2: 338.984 .3

\author{
por \\ José Fariña Jamardo
}

SUMARIO: I. INTRODUCCION.-II. CONCEPTO.-III. ORIGEN-_IV. COMUNIDAD LOCAL Y DESARRÓLLO.-V. ORGANIZACION DE LA COMUNIDAD.-VI. EL DESARROLLO COMUNITARIO EN ESPANA. VII. EL DECRETO 3524/1974: 1. OBJETIVOS SIMULTANEOS DE LAS ACCIONES COMUNITARIAS. 2. REQUISITOS CONCURRENTES QUE CARACTERIZAN LAS ACCIONES COMUNITARIAS. 3. ORGANISM OS A QUIENES CORRESPONDE LA PROMOCIÓN, FOMENTO Y AUTORIZACIÓN DE LAS OBRAS DE ACCIÓN COMUNITARIA. 4. SUBVENCIONES Y AYUDAS. 5. SOlicitudes Y DOCUMENTOS. 6. CONCESIÓN Y LIBRAMIENTO DE LAS SUBVENCIONES. 7. FORMAS DE REALIZACIÓN DE LAS OBRAS. 8. RECEPCIÓN DE LAS OBRAS Y JUSTIFICACIÓN DE LAS SUBVENCIONES CONCEDIDAS.-VIII. CONCLUSIONES.

\section{INTRODUCCION}

La reciente publicación del Decreto 3524/1974, de 20 de diciembre (B. O. del Estado de 13 de enero de 1975), por el que se regula la realización de obras en régimen de acción comunitaria, pone de actualidad la problemática de las acciones de desarrollo comunitario a nivel local y nos brinda la oportunidad de tratar, aunque sea someramente, un tema que ha producido muchos estudios y libros en muy diversos países, sin que haya tenido en el nuestro la resonancia deseada, en especial entre los estudiosos de la Administración local, para los que, salvo contadas y honrosas excepcio- 
nes, el desarrollo comunitario no ha llamado su atención ni ha suscitado comentarios en orden a su incidencia en la Vida local, cuando de hecho la tiene y grande.

Vamos, pues, a analizar lo que significa y representa el desarrollo comunitario y a qué obedece la publicación del Decreto $3524 / 1974$.

\section{CONCEPTO}

Para determinar lo que es "Comunidad» será preciso, como quería TonNies, separarlo de otro término paralelo y con el que algunos lo confunden: «Sociedad». Consideramos a la comunidad como a un agregado de personas cuyas relaciones son íntimas y primarias y entre las cuales el control social se basa ampliamente en usos y costumbres más que en leyes; mientras que la sociedad es el resultado de una creación artificial, de un producto de la inteligencia racional, representando la fase voluntaria y teleológica de la asociación humana.

Para TonNIEs, mientras la sociedad es pasajera, un agregado mecánico y artificial, caracterizada en lo urbano, donde los contactos sociales se basan en los aspectos racionales de una sociedad impersonal, la comunidad es vida común, verdadera, durable, un organismo vivo caracterizado en lo rural, con su énfasis en el parentesco, en la amistad y en la familiaridad prolongada.

Según MAC IVER, comunidad «es una unidad social cuyos miembros reconocen como común un número de intereses suficientemente extensos como para permitir las acciones mutuas de vida en común». El desarrollo, para PERRoux, «es la combinación de cambios mentales y sociales de una población que la vuelven apta para hacer crecer, acumulativa y durablemente, su producto real global».

Ander EGg señala como características necesarias del desarrollo las siguientes: 1. El desarrollo es un aspecto singular del proceso general de cambio social y está ligado más bien a transformaciones mentales y sociales que a factores propiamente dichos. 2 . La dicotomía entre los social y lo económico responde sólo a razones instrumentales. 3. Es necesario concebir el desarrollo en forma equilibrada e integral, teniendo como objetivo último: "Todo el hombre 
y todos los hombres». 4. Un desarrollo integral dotado de verdadero dinamismo, que sea a su vez autosuficiente, no se logra con la decisión a los niveles de tipo gubernamental, con los medios financieros y la reforma de estructuras: es necesario el apoyo y la participación popular desde la base y en todos los niveles.

En cuanto a la expresión Desarrollo de la comunidad, ha venido siendo utilizada por los organismos de las Naciones Unidas desde 1950 para designar aquellos procesos en virtud de los cuales los esfuerzos de una población se suman a los de su Gobierno para mejorar las condiciones económicas, sociales y culturales de las comunidades, integrar a éstas en la vida del país y permitirles contribuir plenamente al progreso nacional. Pero fue a partir de 1958 cuando los organismos de las Naciones Unidas empezaron a utilizar la definición que aún podemos considerar vigente: "Desarrollo de la comunidad es el proceso por el cual el propio pueblo participa en la planificación y en la realización de programas que se destinan a elevar su nivel de vida. Eso implica la colaboración indispensable entre los gobiernos y el pueblo para hacer eficaces esquemas de desarrollo, viables y equilibrados».

Ahora bien, considerando en su contexto y esencia las definiciones anteriores y depurándolas de elementos extraños, podemos decir con PÉREZ Olea que: "El desarrollo comunitario es, en su origen y en su forma más pura, la promoción de los intereses y de las actividades sociales de una comunidad, efectuada a propio impulso y dirección de los interesados".

Al comparar esta definición con el concepto de desarrollo comunitario acuñado por las Naciones Unidas vemos cómo la fórmula inicial y pura de promoción de la comunidad efectuada a propio impulso y dirección de los interesados, es decir, promoción de la comunidad por la propia comunidad, es modificada en el sentido de que si bien la comunidad participa en la planificación y realización de programas destinados a su desarrollo, lo hace en colaboración con los gobiernos - locales, provinciales o nacionales-, a fin de que este desarrollo resulte eficaz, viable y equilibrado. Lo que equivale a decir que la comunidad recibe ayudas oficiales y externas para que su desarrollo se genere coordinado y equilibrado con el de otras comunidades, e implica, por ende, la modificación de ciertas notas originarias del movimiento bautizado con el nombre de desarrollo comunitario. 
Según Pérez OleA, «la traslación del movimiento del desarrollo comunitario a un tipo de necesidades mucho más conocidas y familiares: abastecimiento de agua, electricidad, servicios asistenciales y sanitarios en general, etc., supuso de inmediato desvirtuar algunas de las citadas notas originarias del desarrollo comunitario». Esta modificación de las bases primarias y esenciales del movimiento comunitario fue causa, como señala el mismo autor, de que, por un lado, y salvo en casos excepcionales, «los miembros de una comunidad en estas condiciones no suelen buscar ya la satisfacción autárquica de ese deseo, sino la expresión de una necesidad ante las esferas competentes, que suelen corresponder a los poderes políticos", y por otro, exista cierta tendencia por parte de las comunidades a abandonar en mano de los poderes públicos, incluso la determinación de la forma y medios de atender a las necesidades planteadas, con lo cual «el dinamismo original del desarrollo comunitario, tan perceptible en su estado puro, se transforma ahora en automatismo sin demasiada vida interna". De aquí que los estudiosos del desarrollo comunitario distingan entre desarrollo espontáneo, asistencial e intermedio.

\section{ORIGEN}

Como ocurre con otras disciplinas, el desarrollo comunitario como movimiento, como centro de interés y materia objeto de estudio, tiene un origen reciente, lo que no impide que haya existido prácticamente desde el momento en que los hombres se agruparon en comunidad. Si una tribu construye una citania o un castro, si un clan abandona su sistema de vida errante y se hace sedentario, si una comunidad de aldea construye y aprovecha en común un horno, un molino, un lagar, un puente o un camino, está haciendo, muchas veces sin saberlo, desarrollo comunitario. Y, casi siempre, aún en nuestros días, este desarrollo comunitario es espontáneo. Gracias a él se han electrificado pueblos, construido caminos y carreteras, realizado abastecimientos de aguas y alcantarillado y conseguido elevar, aunque fuese en cuantía mínima, el nivel de vida de muchas comunidades rurales.

Ahora bien, en la forma en que ahora entendemos el desarrollo comunitario como movimiento, su nacimiento tiene lugar, según algunos autores, en los Estados Unidos y a principios de este siglo, 
con las organizaciones de caridad y los clubs para la promoción de actividades educativas y recreativas. Estos clubs facilitaban préstamos y ayudas con el objeto de liberar «las energías durmientes de las comunidades». Y lo curioso de este movimiento es que nace en las ciudades para luego pasar a extenderse a las zonas rurales. Es en el año 1914 cuando se crea en Norteamérica el Agricultural Extension Service, trasplantado bastantes años después a nuestro país con el nombre de Servicio de Extensión Agraria.

El nacimiento de este movimiento, en cuanto representa «una fórmula colectiva de incrementar el bienestar físico y espiritual de cada núcleo humano», puede explicarse considerando que la puesta en marcha del desarrollo comunitario requiere, según PÉREz OLEA, aun índice elevado de sociabilidad y un nivel de vida igualmente alto que permita a los particulares destinar tiempo y esfuerzo al servicio desinteresado del grupo social en el que se inserta». Por eso se produce inicialmente no sólo en los Estados Unidos, sino en los países europeos de mayor bienestar y desarrollo: Escandinavia, Países Bajos y Gran Bretaña.

La expresión "desarrollo de la comunidad» (Community Development), que no se usó en los Estados Unidos hasta el 1947, fue utilizada por el Gobierno inglés en 1942 para designar el movimiento de promoción de sus colonias, concibiendo dicho movimiento como destinado a promover el mejoramiento de la vida de toda la comunidad con su participación activa y, en lo posible, por iniciativa de la propia comunidad. Cuando dicha iniciativa no apareciese de manera espontánea se emplearían técnicas que la hiciesen surgir y la estimulasen con el objeto de asegurar respuestas activas y entusiastas al movimiento.

Esta concepción del desarrollo comunitario acuñada por el Gobierno inglés en 1942 nos ofrece ya los tipos espontáneo y asistencial o dirigido que luego se barajarán en las fórmulas de las Naciones Unidas. Pero en orden a los tipos asistenciales conviene tener presente la observación que NEH RU hacía a los ingleses: "Claro que queremos ayuda, pero, curiosamente, no queremos demasiada. En otros términos, no queremos darle a nuestro pueblo la impresión de que son los otros quienes van a construir la India en su lugar..., los hindúes deben forjar ellos mismos su país». 


\section{COMUNIDAD LOCAL Y DESARROLLO}

En un sentido amplio y con carácter general, la XI Conferencia Internacional de Servicio Social, celebrada en Brasil en 1962, senaló como objetivos a alcanzar en los programas de desarrollo de la Comunidad los siguientes:

- Los primordialmente económicos.

- Los cívicos o socio-cívicos.

- Los socio-económicos.

- Los primordialmente sociales.

Pero, considerando que las comunidades humanas tienen un asentamiento geográfico y desarrollan su actividad dentro de un ámbito territorial determinado, dichos programas habrán de ser:

- Nacionales.

- Regionales.

- Provinciales.

- Locales o comunales.

La comunidad básica es siempre una comunidad local. Por eso, al hablar de desarrollo comunitario, tenemos que referirnos, en primer término, al desarrollo local. Para LevY-STrauss, "los hechos sociales que estudiamos se manifiestan en sociedades que son cada una un ser total, concreto y compacton, y cualquier estructura social, como pone de relieve KISNERMAN, «se concreta en una realidad local».

Pero comunidad, en cuanto expresión de vida común, como senalaba TonNIEs, se caracteriza en lo rural por ser comunidad natural de agrupación, mientras la sociedad urbana, en cuanto comunidad artificial, ha de disgregarse o dividirse para crear verdaderas comunidades sociales. El desarrollo comunitario, sin embargo, puede producirse en los dos sectores, siempre que, como apunta Caroline WARE, constituya «un proceso para suscitar grupos funcionales de ciudadanos capaces de ser los agentes activos y responsables de su propio progreso, usando para ello, como medios, la investigación en común de los problemas locales, el planeamiento y la ejecución por sí mismos de las soluciones que antes convinieron y la coordinación voluntaria con los demás grupos y con las autoridades oficiales, de modo que se obtenga el bienestar total de la comunidad». 
Es posible que, cara al futuro, los conceptos que hoy mănejamos sobre sociedad y comunidad resulten extraños, pero aun en el supuesto de que desemboquemos en la contracultura, las entidades locales primarias conservarán y acrecentarán su importancia. Según Theodore RoszaK: «Los jóvenes empiezan a hablar de que en un mundo que entiende la sociedad como simple auxiliar adjunto cada día más subordinado a un gigantesco mecanismo tecnológico que exige constante e instantánea coordinación del centro, cosas tales como "comunidad" y "democracia de participación" son totalmente impracticables. De esta manera vuelven a un estilo de relaciones humanas característico de la aldea y la tribu, insistiendo en que la única política de hoy es aquella que lleva a la confrontación profundamente personal con todas estas envejecidas formas sociales». Dentro de este orden de preocupaciones, en cuanto a representatividad, figura la puesta de relieve en el II Simposio Europeo del Servicio Social, de Stuttgart, sobre autoridad y comunidad local, o la certeza de que el soñado gobierno a escala mundial exigiría, como ha señalado TOYNBEE, «comunidades de aldea en la base».

El olvido en los programas de desarrollo comunitario de la realidad local y de la necesidad esencial de contar con ella, ha sido causa de muchas decepciones y fracasos, al igual que lo ha sido la formulación de planes sin estar presentes los representantes de estas comunidades. Por eso los primeros estudiosos e impulsores del desarrollo rural sostenían, como hace constar Garcfa FERRANDo, que la comunidad local debía realizar sus propios estudios y planes. «Debemos poner la idea comunitaria dentro de nuestro pensamiento y planificación. Debemos ver la comunidad como unídad cuyo bienestar futuro puede y debe ser planeado con anterioridad. Tiene que desarrollar una comunidad fuerte, viril y agresiva, cuyo espíritu dominante sea: todos para uno y uno para todos».

Este espíritu comunitario no podrá alcanzarse si no se cuenta con la comunidad en la planificación y ejecución de su propio desarrollo, si no están presentes las entidades y Corporaciones locales que representan a estas comunidades. Cuando no se hace así, los programas mejor concebidos fracasan. Podíamos citar muchos ejemplos a escala internacional, pero traemos aquí, como significativo, el comentario que hizo MUKERJI en relación con la ejecución del programa de desarrollo de su país: «El programa de la India ha pasado por la etapa en que se procuraba estimular el 
desarrollo de la comunidad mediante órganos especiales de desarrollo, lo cual dio poco resultado. El esfuerzo actual consiste en crear o mejorar los gobiernos locales y estimular al mismo tiempo las actividades de esfuerzo propio en la comunidad. El fomento de la autonomía local es algo más que una nueva tentativa de crear instituciones populares para el desarrollo de la comunidad. El objetivo consiste en revitalizar todo el proceso democrático y colocar a la nueva democracia del país sobre cimientos más amplios y sólidos».

El estudio de las entidades locales y del gobierno local resulta así fundamental para la programación del desarrollo de la comunidad. Como escribe Ander EGG: «Aun cuando se prescinda del análisis de los otros aspectos de la organización social, tales como la diferenciación social, estratificación, asociaciones, instituciones y formas de control social, el gobierno local, como base administrativa y operacional, debe merecer especial atención».

El Municipio es la entidad local por excelencia que forma una asociación natural de personas y bienes determinada por necesarias relaciones de vecindad y constituye una comunidad humana asentada en un ámbito territorial definido. Ofrece, por tanto, la base ideal, y en cierto sentido única, para un eficaz desarrollo comunitario. «Si se me apura podría decirse - afirma PÉREZ OlEAque el desarrollo comunitario aspira ante todo a revitalizar el sentido social del Municipio. Esto último está, naturalmente, en función de cada clase de Municipios; en la gran urbe, el desarrollo.comunitario tiende a fragmentar, a seccionar, a crear unidades reducidas de fuerte cohesión interna; aquí es, en efecto, donde los fenómenos de masificación se producen con mayor vigor. La creación de pequeñas unidades comunitarias -l barrio, el bloque, el conjunto residencial - con su propia vida social, mediante la intensificación de las interrelaciones de sus componentes, tiende a romper la unidad, a separar al hombre de la masa amorfa y aniquiladora de la personalidad, integrándole en un cerco social vitalmente constituido".

El alcanzar la revitalización del sentido social no precisa en los pequeños Municipios, y aun en los medianos, esta fragmentación en grupos que ha de producirse en la gran urbe. En el concepto clásico podemos hacer equivalentes: pueblo-Municipio-comunidad local. Pero cuando un mal llamado Municipio está formado por varios pueblos es preciso hablar entonces de varias comunidades, a semejanza de lo que ocurre en las grandes urbes. 
La comunidad local es, casi siempre, la comunidad por excelencia. Sin embargo, para que esta comunidad funcione comunitariamente deben coincidir autoridad y comunidad local y actuar cohesionadas, hecho que sólo llega a producirse con plenitud en las entidades locales más reducidas, es decir, en las entidades locales menores o en los pequeños Municipios. Refiriéndose a la distinción entre comunidad y autoridad local, dice PÉrez Olea: «La comunidad local es un concepto sociológico determinado por la adhesión consciente y activa de un grupo convivente y su organización en vista de la consecución de fines propios. La autoridad local, en cambio, responde a una noción político-administrativa basada en el reparto geográfico de competencias».

El reparto geográfico de lạs competencias, con la secuela de realización de acciones paralelas sobre una misma comunidad por diversos organismos e instituciones, se considera a escala internacional, y según nos advierte Ander EGg, como un mal endémico producido por «las rivalidades entre los distintos organismos y reparticiones, con el fin de atribuirse el mérito de las obras realizadas».

\section{ORGANIZACION DE LA COMUNIDAD}

Ninguna comunidad podrá desarrollarse con efectividad si carece de la organización adecuada que le permita programar y ejecutar su propio desarrollo. La organización de la comunidad se consideró como fundamental en la Conferencia Nacional de Servicio Social celebrada en los Estados Unidos en 1943, en la que se discutieron y formularon diversas definiciones, de las cuales destacamos la siguiente: «En el campo del bienestar social, la organización de la comunidad puede describirse como el arte de descubrir necesidades sociales y de crear, coordinar y sistematizar los agentes instrumentales a través de los cuales los talentos y recursos de los grupos pueden ser dirigidos hacia la realización de los ideales del mismo grupo y hacia el desarrollo de las potencialidades de sus miembros. Investigación, interpretación, conferencias, educación, organización de grupos y acción social son los principales elementos usados en este proceso".

Por su parte, Arthur Dun ham define la organización de la comunidad como «un proceso dirigido hacia la creación de recursos 
y el mantenimiento del equilibrio necesario entre tales recursos y las necesidades de una determinada área geográfica o campo específico de servicio social».

Este equilibrio debe mantenerse a fin de que el desarrollo de las distintas comunidades de un país marche paralelo y que los progresos de orden material y de orden social sean parejos. En caso contrario no se puede hablar de desarrollo comunitario. Así lo expresaban los autores del Informe del Brasil a la XI Conferencia Internacional de Servicio Social de 1962: "Un desarrollo que no puede superar el desajuste social, que sea incapaz de favorecer la interacción social de lá comunidad nacional y que no pueda impedir el empobrecimiento cada vez más acentuado de quienes ya son injustamente pobres, ni evitar el enriquecimiento de los que son innecesariamente muy ricos, no es un desarrollo auténtico, pues violenta la dignidad de los hombres y degrada al país».

Dentro de la organización de la comunidad, si queremos llegar a un diagnóstico y planificación de objetivos, tendremos que realizar previamente una investigación que debe abarcar desde el marco histórico y las estructura físicas fundamentales hasta los recursos y potencialidades de la comunidad, pasando por la infraestructura y equipamiento, población y niveles de vida y la organización y los procesos sociales, incluida la percepción del cambio social.

Una vez diagnosticados y clasificados los problemas y determinadas las prioridades, se planificarán los objetivos y se concretarán los programas y proyectos de una forma racional, es decir, adecuando lo posible a lo deseable, para pasar, una vez preparada la comunidad y allegados los medios necesarios al efecto - personales y materiales-, a la ejecución o desarrollo de lo programado, para terminar con la evaluación de los resultados obtenidos.

La planificación del desarrollo comunitario debe ajustarse, en cuanto técnica, a las grandes líneas contrastadas de los modernos sistemas de organización, aunque sin olvidar nunca sus especiales características sociales y comunitarias, pensando y actuando sobre éstas en primer lugar, como indica la FAO en el texto inserto en Social Welfare in Rural Communities: "Para iniciar un servicio en una comunidad, lo que se necesita no es tanto una estadística exacta cuanto una apreciación general del modo de vida $\mathrm{y}$, en particular, del modo de pensar de la población. Un estudio general de los problemas graves, de las personas y de los grupos que pueden ayudar, muchas veces es suficiente para iniciar un trabajo. Por 
otra parte, el investigador hábil puede conocer mucho más en las conversaciones de café que a través de cuestionarios. Es conveniente dejar la investigación sistemática para el momento en que se necesita la información detallada y después de haber logrado la confianza del pueblo».

\section{EL DESARROLLO COMUNITARIO EN ESPAÑA}

Como acción, en todo o en parte programada, el desarrollo co. munitario en España es reciente y, además, se ha realizado sin tener en cuenta a la entidad verdaderamente representativa de la comunidad local que es el Municipio.

Los autores, y entre ellos Amado Solfs, señalan como entidades de acción comunitaria más destacadas en España los centros sociales de la Iglesia católica, singularmente Cáritas; las actuaciones de la Sección Femenina; los Patronatos de la Vivienda, y la Red Nacional de Tele-Clubs. A estas entidades habrá que añadir en los últimos años, y con acciones que alcanzaron cierta efectividad e importancia, sobre todo en las zonas rurales, al Servicio de Extensión Agraria, del Ministerio de Agricultura, y al Instituto Nacional de Previsión, a través de la Mutualidad Nacional Agraria y de sus Comisiones Provinciales y Locales, con las aportaciones de fondos destinados a cubrir las prestaciones de empleo comunitario para prevenir o combatir el paro, canalizadas a través de las Hermandades Sindicales de Labradores y Ganaderos, y que, partiendo de la Ley núm. 41/70, de 22 de diciembre, se desarrolla en las Ordenes de 14 de enero y 24 de septiembre de 1971.

La asignación de competencias a la Dirección General de Capacitación y Extensión Agrarias, del Ministerio de Agricultura, en cuanto al desarrollo comunitario en las zonas rurales, se hace por Decreto 2684/71, de 5 de noviembre, que reorganiza dicho Ministerio, y en cuyo artículo 15 se establece que la citada Dirección «tendrá a su cargo la dirección, gestión y ejecución de las acciones encaminadas a que los agricultores y sus familias intervengan eficazmente en el necesario desarrollo socio-económico del sector al que pertenecen».

Sin embargo, y aunque no hayan sido estudiadas, las acciones de desarrollo comunitario a nivel local sí se han venido produciendo en nuestro país, y desde hace muchos años. Estas acciones han 
tenido un carácter espontáneo y se han desarrollado sin continuidad, coordinación ni planificación. Nos referimos a las acciones de entidades locales menores o de entidades sociales no oficiales, como aldeas, parroquias y pueblos, integradas dentro de un Municipio, las cuales han hecho desarrollo comunitario - al igual que muchos pequeños Municipios- con verdadera promoción de los intereses y de las actividades sociales de la comunidad, efectuándolo a propio impulso y dirección de los interesados.

De muchas de estas acciones se han ocupado la prensa y los medios de comunicación social. Son los vecinos de una aldea que con su propio impulso, trabajo y dirección construyen una carretera que enlace la aldea con la carretera general, venciendo así el aislamiento en que vivían. Son los feligreses de una parroquia que, "uno para todos y todos para uno», conducen el agua a sus aldeas y a sus casas, construyen el alcantarillado y pavimentan las calles. Son los moradores de un pueblo que aportan el dinero, los postes, los hilos y el trabajo para que cualquier compañía eléctrica les lleve la luz... y se la cobre. El líder que mueve la aldea, la parroquia o el pueblo es el emigrado que regresa o que viene de vacaciones, el mozo avispado e inquieto que ama a la comunidad en que vive y desea su progreso, el sacerdote o el maestro y, a veces, una Juana de Arco aldeana de las que, con bastante frecuencia, surgen en las zonas rurales de nuestro país, en las zonas huérfanas de jóvenes y de hombres.

En muchas ocasiones - aunque no siempre- el Municipio interviene en estas acciones de desarrollo comunitario espontáneo con aportaciones de materiales: pólvora, cemento, asfalto; de maquinaria y herramientas, o de tipo económico: pequeñas subvenciones en metálico. A veces, los Ayuntamientos aprovechaban determinadas subvenciones, como las de Paro Obrero, para impulsar estas realizaciones y las acciones espontáneas del desarrollo comunitario, con lo que el esfuerzo vecinal obtenía determinadas ayudas estatales para electrificaciones, pequeños regadíos, abastecimientos, etc., a través del Instituto Nacional de Colonización y de otros organismos de diferentes Ministerios, aliviando la carga vecinal y logrando mejores frutos.

En este sentido podemos decir que el desarrollo comunitario se ha producido de hecho en la esfera de lo local en muchos casos, especialmente en las entidades de menor población, sin olvidar que en algunas grandes urbes las asociaciones de vecinos de calles o 
barrios han impulsado este mismo desarrollo y obtenido algunos logros al respecto. También han sido realizadas acciones para el desarrollo comunitario de pueblos, ciudades y Municipios, impulsadas por centros y asociaciones privadas de carácter local, especialmente en Levante y Cataluña.

Pero, aparte de estos brotes esporádicos e inconexos de desarrollo comunitario, que no constituyen en modo alguno un movimiento en tal sentido, las acciones dirigidas que han intentado diversos organismos y entidades confesionales, institucionales o gubernamentales se han realizado en España por distintos caminos y sin una coordinación adecuada, produciéndose sobre un mismo término municipal distintas e inconexas, sin tener en cuenta al organismo verdaderamente representativo $\longrightarrow$ que al menos como tal se concibe- de la Vida local y la comunidad que es el Municipio.

Por eso, y hasta la publicación del Decreto 3524/1974, del que seguidamente nos vamos a ocupar, en España seguían teniendo vigencia las palabras de Pérez Olea, publicadas en 1964: «No es un secreto, con todo, que el desarrollo comunitario está en sus albores entre nosotros y se encuentra en una posición delicada, fragmentado entre decenas de organismos religiosos, públicos, semipúblicos y privados, que con sus bienintencionados esfuerzos hacen cada día más difícil la auténtica promoción de la comunidad como entidad unitaria social. Para mí está claro que la solución sólo puede venir, en la gran mayoría de los casos, de una institución; de una institución que, salvo excepciones no muy numerosas, ha permanecido cuidadosamente al margen de este movimiento. Esta institución es, naturalmente, el Municipio».

Señala el mismo Pérez Olea que la aportación del Municipio al desarrollo comunitario puede sintetizarse en las siguientes notas: «1) Una unidad básica territorial; 2) Una unidad administrativa de gestión; 3) Un canal de comunicación con organismos superiores; 4) Una autoridad política interna; 5). Un medio de crecimiento aséptico, pero no agnóstico».

\section{EL DECRETO $3524 / 1974$}

Ha sido publicado el 13 de enero de este año 1975 para regular la realización de obras en régimen de acción comunitaria. En su preámbulo considera que el equipamiento en servicios colectivos 
de núcleos rurales es una legítima aspiración de la población afectada, lo cual responde a una exigencia de justicia social y constituye una preocupación del Gobierno, decidido a hacer llegar a todos los españoles los frutos del progreso socio-económico del país.

Resalta la «especial importancia de la incorporación de la propia población a las tareas del desarrollo, de modo que sin limitarse a la simple recepción de beneficios participe activamente en su creación y gestión». Y señala que "las experiencias existentes demuestran que ambos objetivos se pueden alcanzar mediante la participación activa y responsable de la población rural en acciones de desarrollo comunitario dirigidas a satisfacer necesidades de equipamiento colectivo, porque permiten adoptar soluciones asequibles a la economía de los afectados, facilitando su aportación en equipo y trabajo $\mathrm{y}$, sobre todo, porque hace que se sientan protagonistas de sus propias iniciativas». Además de en las zonas rurales, pone de relieve que estas acciones de desarrollo comunitario se han realizado con éxito, igualmente, en zonas suburbiales de núcleos urbanos.

Partiendo del hecho de que en muchos casos estas acciones se traducen en la ejecución de obras e implantación de servicios de carácter eminentemente local, resalta la conveniencia de aunar la actuación de la iniciativa comunitaria con la de las entidades locales y la Administración central, de manera que dichas acciones puedan ser objeto de los Planes Provinciales y cuenten con la colaboración económica del Estado.

Hace luego historia de cómo el Decreto 2684/1971 dispuso que la Dirección General de Capacitación y Extensión Agrarias, del Ministerio de Agricultura, tendría a su cargo la dirección, gestión y ejecución de las acciones encaminadas a mejorar el entorno social de la población agraria, y cómo el Servicio de Extensión Agraria, actuando permanentemente dentro de las comunidades rurales, orientó el proceso de desarrollo de la comunidad con base en la unión voluntaria de esfuerzos y recursos de los afectados.

Teniendo en cuenta tales circunstancias y el hecho de que «la mutua colaboración de las Direcciones Generales de Capacitación y Extensión Agrarias y Administración Local, a través del Servicio de Extensión Agraria y el sistema de Planes Provinciales, se ha traducido en la realización de un importante número de obras y servicios para el bienestar social y en la positiva evolución en las aptitudes y capacidades de la población participante», el Consejo de Ministros, a propuesta de los de la Gobernación y Agricultura, 
aprobó este Decreto 3524 en su reunión de 20 de diciembre de 1974. El Decreto, promulgado en la misma fecha de su aprobación, se publicó en el Boletín Oficial del Estado, número 11, del 13 de enero de 1975, y en los doce artículos de que consta establece:

\section{OBJETIVOS SIMULTÁNEOS DE LAS ACCIONES COMUNITARIAS}

a) La mejora del medio rural y barriadas urbanas mediante un mejor aprovechamiento de los recursos disponibles que permita a sus habitantes unas adecuadas condiciones de vida.

b) El desarrollo de las comunidades rurales en orden a aumentar su capacidad para resolver problemas cuya solución requiera la unión de recursos, esfuerzos y voluntades.

2. REQUISITOS CONCURRENTES QUE CARACTERIZAN LAS ACCIONES COMUNITARIAS

a) Libre determinación de los vecinos en la elección de los problemas que desean resolver.

b) Participación y protagonismo de aquéllos en las posibles soluciones de tales problemas.

c) Voluntariedad en la participación y protagonismo citados.

d) Facultad de dichos vecinos en la adopción de acuerdos sobre la forma de organizarse y de elegir a las personas que han de constituir la comisión gestora de la acción comunitaria.

e) Ejecución directa de las obras por el vecindario con su aportación personal y económica.

3. ORGANISMOS A QUIENES CORRESPONDE LA PROMOCIÓN, FOMENTO Y AUTORIZACIÓN DE LAS OBRAS DE ACCIÓN COMUNITARIA

a) Al Servicio de Extensión Agraria, el promover y orientar la acción de las comunidades en las distintas fases del proceso, velando especialmente por el cumplimiento de los fines educativos y prestando cuanta ayuda sea precisa a las personas y entidades interesadas en la promoción y orientación de estas acciones comuni- 
tarias, de modo que su planteamiento y metodología satisfagan plenamente el espíritu y objetivos del sistema.

b) A las entidades locales, dado el carácter municipal de las obras realizadas por este sistema, incumbe fomentar las mismas y autorizarlas en su caso, solicitar las ayudas precisas, supervisar su ejecución y vigilar su realización con las debidas garantías técnicas y, una vez terminadas, si procediere, incorporarlas a su patrimonio. Por su parte, las Diputaciones provinciales procurarán prestar la oportuna asistencia técnica en la redacción de proyectos y dirección de las obras.

\section{SUBVENCIONES Y AYUDAS}

Las obras de acción comunitaria podrán ser subvencionadas:

a) Hasta un 25 por 100 de su presupuesto total con cargo al crédito de Planes Provinciales.

b) Con otro 25 por 100 del presupuesto de las obras, procedente de los fondos propios de las entidades locales correspondientes, y sin que pueda exceder de dicho porcentaje, debiendo la aportación, que se efectuará en forma de materiales adquiridos mediante el sistema legal de licitación, ser autorizada conforme a la legislación vigente.

c) Si, además de las anteriores, hubiere alguna otra ayuda de carácter público, el conjunto de subvenciones no podrá sobrepasar el 50 por 100 del presupuesto total de las obras.

\section{SOLICITUDES Y DOCUMENTOS}

Decidida por la comunidad de vecinos la realización de la obra o implantación del servicio, el Ayuntamiento o entidad local menor de que se trate formulará solicitud de subvención, presentándola a la Comisión Provincial de Servicios Técnicos, la cual, previo estudio y conformidad en su caso, la elevará a la Comisión Interministerial de Planes Provinciales. A dicha solicitud se acompañarán los siguientes documentos:

a) Proyecto o memoria descriptiva y valorada de la obra a realizar, con expresión del plazo previsto para su ejecución. 
b) Conjunto de acuerdos adoptados por los vecinos para la realización de la acción comunitaria, firmados por todos los participantes, señalando expresamente el compromiso de completar la financiación de la obra mediante la aportación de trabajo, transporte o metálico, así como de asumir los riesgos que pudieran surgir con ocasión de la prestación antes citada, acreditando a tal fin haber concertado la oportuna póliza de seguro.

c) Informe del Jefe del Servicio Provincial de Inspección y Asesoramiento de las Corporaciones Locales sobre si las subvenciones concedidas por las entidades locales reúnen las condiciones legales y otros extremos que estimen de interés en relación con lo dispuesto en el presente Decreto.

d) Informe de la agencia comarcal correspondiente del Servicio de Extensión Agraria en el que se manifieste si se cumplen los objetivos y requisitos establecidos en los artículos primero y segundo del Decreto y cualquier otro extremo que se considere de interés.

\section{CONCESIÓN Y LIBRAMIENTO DE LAS SUBVENCIONES}

a) La concesión de subvenciones corresponde al Consejo de Ministros, a propuesta de la Comisión Interministerial de Planes Provinciales, con cargo-al crédito_de Planes Provinciales.

b) Una vez concedidas las subvenciones se librarán. a nombre del Ayuntamiento respectivo, contabilizándose en valores independientes del presupuesto, como-afectas a la exclusiva finalidad de la ejecución de la obra o servicio de que se trate:

\section{FORMAS DE REALIZACIÓN DE LAS OBRAS}

a) Dado que las obras realizadas en régimen de acción comunitaria se llevan a cabo por ejecución directa del vecindario, quedarán exceptuadas de las normas de contratación de régimen local.

b) La aportación económica de las Corporaciones locales será exclusivamente en materiales, que se adquirirán conforme a las normas de contratación administrativa local.

c) No obstante podrán ejecutar estas obras las entidades locales, conforme a la normativa de contratación local, en los casos que no sea posible su ejecución directa por el vecindario. 
8. RECEPCIÓN DE LAS OBRAS Y JUSTIFICACIÓN DE LAS SUBVENCIONES CONCEDIDAS

a) La entidad local que haya de recibir las obras recabará previamente los informes técnicos que estime oportunos sobre su ejecución y adecuación al fin propuesto y resolverá como estime procedente sobre su incorporación al patrimonio municipal o de la entidad local menor.

b) La justificación de las cantidades concedidas como subven. ción a esta clase de obra se hará mediante las correspondientes certificaciones técnicas, siempre que fuere posible, $\mathrm{y}$, en otro caso, con informe técnico de su ejecución y recepción de las Comisiones Provinciales de Servicios Técnicos, las que podrán vigilar en todo caso su ejecución. Un duplicado de dicho informe se entregará en todo caso al Ayuntamiento interesado y servirá también de justificante de la subvención municipal, si ésta existiese.

Finalmente, señala el Decreto que por los Ministerios de la Gobernación y de Agricultura, en la esfera de sus respectivas competencias o conjuntamente, podrán dictarse las normas que se estimen necesarias para la aplicación del mismo.

\section{CONCLUSIONES}

La forma en que hemos desarrollado este pequeño trabajo nos permite establecer comparaciones para determinar hasta qué punto los conceptos teórico-doctrinales del desarrollo comunitario han sido recogidos en el Decreto 3524/1974, y en qué manera la realización de obras en régimen de acción comunitaria, que el Decreto preconiza, pueden considerarse desarrollo comunitario; al igual que la importancia que el mismo reviste para las Corporaciones locales y las innovaciones que supone en el régimen municipal vigente.

En este, sentido, y a modo de conclusiones, anotamos las siguientes:

1. ${ }^{\text {a }}$ El Decreto 3524/1974 reconoce el carácter municipal de las obras realizadas en régimen de acción comunitaria y asigna al Municipio una misión de fomento, autorización, promoción, supervisión y vigilancia de dicha acción. Este reconocimiento viene a poner fin a una situación anterior en la que el desarrollo comunitario, a escala local o superior, parecía ignorar, y de hecho prescindía, de la existencia del Municipio. 
2. Aun cuando la acción comunitaria dentro de un término municipal se hará en el futuro coordinada y con intervención del Ayuntamiento respectivo, esta coordinación a escala oficial e institucional sólo afecta a los Ministerios de la Gobernación y de Agricultura y no comprende las acciones de otros Ministerios y organismos del Estado o institucionales, como, por ejemplo, las aportaciones de fondos de la Mutualidad Nacional Agraria destinados a cubrir las prestaciones de empleo comunitario.

Para alcanzar los principios que hemos expuesto y la deseada efectividad, es preciso que toda la acción de desarrollo comunitario local sea centrada, autorizada, promocionada y vigilada por el $\mathrm{Mu}$ nicipio respectivo.

3. ${ }^{\text {a }}$ El Decreto $3524 / 1974$ no regula realmente todo el posible desarrollo comunitario, sino un aspecto concreto del mismo: la realización de obras en régimen de acción comunitaria, aunque sus objetivos sean, como señala el artículo $1^{\circ}$, por un lado, la mejora del medio rural y barriadas urbanas $y$, por otro, el desarrollo de las comunidades rurales en orden a aumentar su capacidad para resolver problemas cuya solución requiera la unión de recursos, esfuerzos y voluntades.

En términos generales, su concepción se ajusta a los moldes acuñados por los organismos de las Naciones Unidas para el desarrollo comunitario, ya que es el propio pueblo quien solicita las obras y participa en la realización de las mismas, lo que supone la colaboración indispensable entre comunidad y Gobierno, según se deduce del artículo $2 .^{\circ}$ del Decreto, que caracteriza como acciones comunitarias aquellas en que concurren los requisitos de: elección libre por los vecinos de los problemas que desean resolver; participación y protagonismo de los vecinos en las posibles soluciones a los problemas; voluntariedad en la participación; facultad de adoptar acuerdos sobre la forma de organizarse y de elegir a las personas que han de constituir la comisión gestora de la acción comunitaria, y ejecución directa de las obras por el vecindario con su aportación personal y económica.

Pero este desarrollo comunitario no puede calificarse de espontáneo, sino de asistencial o intermedio, puesto que es ayudado, dirigido y controlado fuera de la propia comunidad y está destinado a cubrir un tipo de necesidades y servicios que desvirtúan algunas de las notas originarias del desarrollo comunitario, facilitando la 
posibilidad de que las comunidades abandonen en mano de los poderes públicos la determinación de la forma y medios de atender a las necesidades planteadas.

4. ${ }^{a} \quad$ El Decreto 3524/1974 supone un primer paso en cuanto a una regulación efectiva y necesaria del desarrollo comunitario a escala local, pero se limita a un aspecto tan sólo de la acción que es preciso desarrollar en este sentido y que debe abarcar, como ya pusimos de relieve, «todo el hombre y todos los hombres».

5. Aun dentro de sus limitaciones, el Decreto puede ser un acicate para liberar una parte de las «energías durmientes» en nuestras comunidades y ofrece a los Municipios, especialmente a los rurales y deprimidos, ciertas posibilidades de acción comunitaria real si saben remover el sentido vecinal y comunitario y canalizar las fuerzas que en cualquier comunidad viva existen. La fórmula que brinda el Decreto es clara: ayúdate y te ayudaremos. $Y$ las posibilidades de acción en cuanto a realización de obras y servicios, muchas.

6. El Decreto afecta a la legislación vigente de Régimen local, en cuanto exceptúa de la subasta la realización de las obras de acción comunitaria, excepción necesaria y lógica dada la especialidad de su ejecución. También, en cuanto abre una fuente importante para el incremento del patrimonio municipal. Las disposiciones de orden contable y de control y justificación de ayudas son prácticamentè las mismas que rigen para otras subvenciones, aunque más sencillas.

Es de esperar que a la pequeña burocratización que el Decreto impone para la realización de obras en régimen de acción comunitaria se le dé por los organismos y funcionarios implicados la máxima agilidad para que el desarrollo y los anhelos de las comunidades no se vean frenados o ralentizados. Y que los créditos de Planes Provinciales para este fin permitan realmente hacer efectivo e importante el desarrollo comunitario local.

7. Ciertamente, y en primer lugar, han de ser las propias comunidades las que deben integrarse y participar: todos para uno y uno para todos; pero a los Ayuntamientos les corresponde también, como representantes de la comunidad, impulsar esta integración y participación comunitaria, poniendo al servicio de la misma todos los medios materiales y espirituales a su alcance, conscientes de que la inercia o el fracaso de la comunidad será su propio fracaso. 
REVL-1975, núm. 186. FARIÑA JAMARDO, JOSE. EL DESARROLLO COMUNITARIO EN EL DECRE...

\section{REVISTA}

ESTUDIOS
DE LA
VIDA LOCAL

\section{CRONICAS}


REVL-1975, núm. 186. FARIÑA JAMARDO, JOSE. EL DESARROLLO COMUNITARIO EN EL DECRE... 